\title{
The Regional MBA: Distinct Segments, Wants, And Needs
}

Kirsten Passyn, Salisbury University, USA

Memo Diriker, Salisbury University, USA

\begin{abstract}
MBA Programs in top-tier school differ greatly from those in regional schools. A survey that aimed at assessing segmentation, pedagogy, and satisfaction in regional MBA programs was developed and administered in three universities of the Mid Atlantic, Midwest, and Southern regions. The results show four clearly distinguished segments that typically attend MBA regional programs: young, standard, manager, and executive. Results in terms of pedagogy and satisfaction reveal that to best meet these segments' needs, regional programs need to design curriculums specifically tailored to their target segments. A one size fits all approach to the regional MBA fails to prepare the students to act in the workplace according to their goals and needs.
\end{abstract}

Keywords: MBA; Top Tier; Regional; MBA Segments; Regional MBA Curriculums

\section{INTRODUCTION}

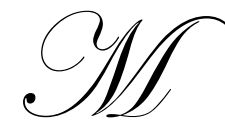

student.

ark graduated from UPENN with a 3.7 GPA and worked for 5 years at Solomon Smith Barney in Investment Banking. Wanting to change career tracks to private equity he took the GMAT, scoring 720 , and will be attending Harvard in the fall. Mark is the stereotypical top tier MBA program

Michael went to a community college for two years before transferring to Towson University and graduating with a 3.4 GPA. Upon graduation he started working as an assistant manager for a regional business where he had worked part time on the floor in the summers since his freshman year in college. After 6 years he was promoted to senior level manager. This promotion along with his projected career path with the firm has made him decide to get his MBA part time. He earned a 520 on his GMAT and will be attending Salisbury University in the fall. Michael is reflective of a type of regional MBA program student. Mark and Michael are very different students in terms of academic background, career experience, and career goals, and therefore, represent different MBA target segments.

Recent research has highlighted the inadequacies of North American MBA programs. Most recently Datar, Garvin, and Cullen (2010) published a book on the shortcomings and potential solutions for the MBA. However, most of this research focuses on a narrow set of top tier schools (e.g. Wharton, Stanford, Harvard). Assuming that what is done by the top programs is duplicated and followed by the regional programs. In contrast, we propose that these programs recruit and educate a unique segment of students with unique backgrounds and career goals. For example Datar, Garvin, and Cullen (2010) state that the majority of top tier MBA graduates seek and move on to careers in investment banking, private equity, hedge funds, or consulting. In fact it is not uncommon for over $50 \%$ of top tier MBA program graduates to take jobs in the financial services. Given this unique segment the question arises if the findings of these studies apply to regional MBA programs, where the students come from different academic and career backgrounds and have different career goals.

In fact, of the nearly 500 AACSB accredited schools in the U.S., at most 100 could be considered top tier programs. Therefore, we argue that over $80 \%$ of these schools cater to a very different segment (or segments). While there are consistencies among top tier and regional MBA programs, we propose that the target segments of each are unique. Given our assertion, we further propose that these programs need to do a better job addressing their 
segments' unique wants and needs. What is true for all business entities is true for MBA programs as well—one size does not fit all.

The purpose of this research is five fold. First, we will briefly review relevant MBA literature. Second, we will identify segments within the regional MBA student population, illustrating how they differ from the top tier MBA segment. Third, we will assess the curriculum of regional MBAs; making needs comparisons between segments and discussing how they differ from top tier programs. Fourth, we will evaluate student assessment of regional MBA programs highlighting differences among segments. Finally, we will make recommendations geared toward regional MBA programs.

\section{BACKGROUND}

In 1959 the Ford Foundation and Carnegie Corporation report on the status of Business Schools was released. The findings indicated that the research and theory being developed in business schools was unsophisticated and unscholarly. The recommendation was that business schools should model themselves more closely on traditional arts and science departments. And in terms of students they should focus on delivering "a high level of analytical ability as well as a sophisticated command of analytical and research tools derived from the fundamental disciplines." The report resulted in a shift in business schools to more closely model their academic cousins with faculty becoming more research and theory oriented and teaching accordingly (Rond and Miller 2005). Although this legitimized business faculty in the eyes of their academic peers, with time, it alienated them from business practice. Top tier academic business journals prefer theory development and rigor to applied managerial insights, so academics read academic journals and managers don't (Cullen 2007).

As in research in teaching, the gap between theory and practice grew (Van de Ven and Johnson 2006). Coursework started focusing on analytical models and quantitative techniques reflecting a new emphasis on hard skills. The result was that MBA programs were creating students capable of analysis but not necessarily action (Datar, Garvin, and Cullen (2010). This gap became more critical as the business environment became more ambiguous and challenging (e.g. rapidly changing technology), and resulted in executives complaining that MBA had the ability to analyze a model but not adapt and apply it, and to assess but not determine and conclude (Schoemaker 2008). The belief that the MBA was in crisis was gaining traction.

The majority of this research, focused on Top Tier MBA programs, was conducted by faculty members at these institutions and therefore primarily reflects these elite programs. For example Chapman (1998) determined the quality signals of the MBA program including: nationally prominent firm recruitment, MBA faculty who consult with major corporations, and Graduates who are leaders in their field. This research was however conducted on Boston College MBAs, a top 50 program. The students at these programs, as reflected in our opening vignette, have different academic backgrounds, experience, career goals, and therefore, different wants and needs. In other words they are truly distinct segments.

Furthermore, the faculty teaching in these programs typically have more elite academic training and are more likely to exclusively publish in theoretical and methodologically rigorous top tier journals bypassing more practically oriented second and third tier journals. Additionally, as suggested above they are more likely to consult for major corporations and interact with top tier executives thru executive education. In contrast regional University Professors are more likely to consult for small and mid-sized companies and interact accordingly with these executives. This suggests that the MBA classroom experience may also differ. Therefore not only should the target segments differ, their wants and needs differ, but the experience should also differ.

Some previous research has focused on MBA market segmentation. For example Daily, Anderson, Ingenito, Duffy, Krimm, and Thomson (2006) determined thru interviews and personal narratives that needs segmentation based on Maslow's Hierarchy could be applied to MBAs. They even suggested that MBA candidates with a need for social status elevation would be more likely to apply to elite programs than candidates with a need for learning. However, the focus of this research was not on identifying how needs and wants of regional versus top tier MBA segments differed but on a general needs based segmentation schema. Leaving unanswered not only how these segments differ but also how their experience differs. 
Evidence suggesting differences between top tier and lower tier Universities does exist. For example, Lawton and Lundsten (1998) found that students at a private, mid-sized, Midwestern university reported that their analytical and statistical skills did not reach their pre-program expectations. However, the drop between expectations and experience was not significant in terms of decision making ability. Additionally, there was also a significant increase in interpersonal skills with students realizing more of these than expected. Perhaps suggesting that the hard skill focus at top tier programs at the cost of soft skills is not equally realized in regional programs either because the student needs are different and/or because the programs themselves are different.

Further research on the differences between top and second-tier MBA programs was published in a Business Week article from 1999. After examining and comparing fifty schools, the author noted that innovative curriculums, lower costs, looser admission requirements, as well as financial aid and a quicker return on investment are some aspects that graduate students and recruiters highlighted in the survey conducted. The article, which lists the factors as reasons to consider lower tier programs, suggests that the factors go along with the wants and needs of students. For instance, in order to forego less income, students would enroll in second-tier MBAs that are not only less expensive, but also offer accelerated programs.

Our study differs from the above research in multiple ways. First, we look at data from multiple programs simultaneously. Second, our multiple sample approach allows us to identify the different wants and needs of different segments of regional MBA students. Third, our research was conducted in 2010 post economic recession. Finally, the focus of our research is different in that our intent is to assess regional MBA segments and how they differ from the top tier MBA segment. In summary, the purpose of this paper is to initiate the investigation into regional MBA program segments.

\section{METHOD}

\section{The Sample}

We ran our survey on $102 \mathrm{MBA}$ students at 3 public, non-urban, regional, Universities located in the Mid Atlantic, Midwest, and Southern regions. Students were enrolled at AACSB accredited programs from Universities of regional although not national distinction. The students at these Universities received an email from the MBA program director asking them to complete a survey assessing their experiences and opinions of their MBA program, assuring all participants that their responses would be completely anonymous and the results would be used to assess the program. Students were given 2 weeks to complete the survey using Survey Monkey, a web-based survey software. Two reminder emails followed up on the first survey email. The response rate among all three schools was $70 \%$.

\section{The Survey}

The survey, which took approximately 20 minutes to complete, consisted of between 55 and 90 questions. As incentive to participate we offered to include additional questions to our survey as per the Universities' request. The survey included both open ended and 7-point likert scale questions. We only discuss those questions relevant to our research and consistent across the three surveys here.

A series of demographic and program motivation questions were used with the intent of helping us to demographically and psychographically identify the different segments of regional MBA students. Examples of these questions include: age, years of work experience, current work status, and motivation for enrolling in the program. [See appendix A for a comprehensive list of these and other questions included in the survey].

A series of program content questions were used to assess pedagogy (or course work) and actual program content. These questions were designed to directly and indirectly assess hard versus soft skill focus. Examples of these questions include: What subject areas are covered in your program? What programs and software have you learned and used in your program? How heavily does your program emphasize presentation skills? How heavily does your program emphasize case analysis? How much emphasis is placed on hard vs. soft skills in your program? 
Finally, a series of program evaluation questions assessed students' satisfaction with the program. Examples of these questions include: How much have you learned in your program? Do you feel the program was a good value for the money? Would you recommend the program to others? As respondents were not required to answer all questions, response rates to the questions above vary.

\section{RESULTS}

\section{Segmentation}

Demographics

Our sample population consisted of 56\% male and $44 \%$ female with an average age of 28 and an average work experience of 5.6 years This is exactly the same demographic expected at top tier programs (Abelson 2010). However, this is only the superficial story; the age range of respondents goes from 20 to 57, and work experience from 0 to 37 years. These ranges are both outside that of top tier programs. The results suggest that regional programs attract both younger and older students with significantly more and less work experience. Regional programs, therefore, include a broader range of segments.

In addition, only $4 \%$ of our population indicated that they were not working at all while $53 \%$ indicated that they were currently working full-time, defined as 40 hours a week or more. The remaining $43 \%$ indicated that they were working part-time, or around 20 hours a week. Respondents from these programs included both full- (54\%) and part-timers $(46 \%)$, so on the surface the results seem logical. However, fewer respondents indicated being parttime students than working full-time, suggesting that at least a small percentage of students are both working and going to school full-time. Furthermore, the full-time and part-time programs at these schools are often intermixed, that is full-time and part-time students take the same courses together. This is possible because most course offerings are in the evening unlike top tier programs, which offer both a full-time, day program, and an executive, weekend program. Regional programs, being just that regional, tend not to have the population base to attract a significant enough number of full and part-time students to support two independent programs.

In summary, in a single classroom you can find a 53 year old with some 30 years of work experience working in groups with a 20 year old that has no managerial experience. In other words, demographically distinct segments are rolled into a single program; taking the same courses and learning the same material.

\section{Psychographics}

In addition to demographic differences we also expected psychographic differences among respondents. Following research on top tier programs, the primary reason for enrollment in top-tier MBA programs is salary increase and career change (Hsu, Chao, and James 2009). In response to the question "What was your primary goal in enrolling in your program?" an independent coder classified the responses into 7 categories. A second coder then classified the responses into these same categories; any differences were resolved thru discussion. The seven categories as well as the frequency of responses follow: 1. knowledge and personal fulfillment (27\%), 2. promotion in one's current employment $(19 \%), 3$. increased salary in a new job $(10 \%), 4$. career change $(10 \%)$, 5. recession related job loss/job search concerns (9\%), 6. entrepreneurial or to acquire skills to start a company (8\%), and 7. other $(17 \%)$. Although several respondents did mention career change and increased salary as reasons for getting an MBA, knowledge and personal fulfillment as well as promotion within one's current employ were the clear leaders.

Supporting the idea that a large percentage of regional MBAs are more interested in what they can learn to improve themselves within their current employ than reposition and advance themselves in the market was the percentage of students who indicated that they were extremely likely to stay with their current employer upon graduation (36\%). This number is driven by the older segments with more work experience. Of those with 6 or more years of work experience, $62 \%$ indicated that they were extremely likely to stay with their current employer, while only $4 \%$ of those with 5 or less years of work experience indicated the same. See Table 1 for an overview of the demographic and psychographic profile of the sample. 
Table 1

Demographic \& Psychographic Profile of the Sample

\begin{tabular}{lc}
\hline & Percent \\
\hline Sex & $56 \%$ \\
\hline Male & $44 \%$ \\
Female & $43 \%$ \\
\hline Age & $18 \%$ \\
\hline Under 24 & $18 \%$ \\
$24-27$ & $21 \%$ \\
$28-30$ & $4 \%$ \\
Over 30 & $43 \%$ \\
\hline Employment Status & $53 \%$ \\
\hline Not Working & $54 \%$ \\
Part-Time & $46 \%$ \\
Full-Time & \\
\hline Enrollment Status & $27 \%$ \\
\hline Part-Time & $19 \%$ \\
Full-Time & $10 \%$ \\
\hline Enrollment Reason & $10 \%$ \\
\hline Knowledge/Fulfillment & $9 \%$ \\
Promotion (w/in employ) & $8 \%$ \\
Promotion (new employ) & $17 \%$ \\
Career Change & \\
Job Search & \\
Entrepreneurial & \\
Other & \\
\hline
\end{tabular}

Discussion

In summary, not only can regional MBAs be segmented by age and work experience but also by their motivation and MBA related goals. As such we created four groups of respondents based on work experience. The young segment has between 0-2 years of work experience, an average 22 years of age, and was most likely to list salary and job search concerns as reasons for getting an MBA. The standard segment-so called because they most reflect the average MBA student-has between 3-5 years of work experience, averages 26 years of age, and was most likely to identify salary and career change or entrepreneurial as reasons for attending the MBA. The manager has moderate work experience (6-10 years), averages 29 years of age, and was most likely to list promotion in one's current employment as his/her reason for enrolling in the MBA. The executive has 11 or more years of work experience, averages 40 years of age and was most likely to list knowledge and personal fulfillment as a reason for attending the MBA. Given the diversity in age, work experience, and goals among these segments, they should likely have both different program content needs and varying program assessment. We address these next.

\section{Pedagogy}

We initially reviewed the pedagogy data across all respondents, by school, and then by segment. The assessment showed only marginal differences among schools. This high degree of consistency among schools enabled us to analyze the data across schools, increasing power. We present both the general results and by segments results below. As all three programs do not segment their student population and the full- and part-time programs are integrated, relatively few variations by segments were observed in terms of actual curriculum experience. (Any such differences are discussed below). However, interesting differences in terms of preference by segment did occur.

\section{Function Coverage}

In terms of business functions, over $95 \%$ of respondents indicated that Management, Finance, and Accounting were comprehensively covered. In addition, over $90 \%$ of respondents indicated that Marketing, Information Systems, and Ethics were comprehensively covered. However, only 50\% or less indicated that Logistics, Forecasting, and Economics were comprehensively covered. 


\section{International Focus}

Next, students answered a scale question $(1=$ not at all emphasized, $4=$ moderately, $7=$ heavily emphasized) concerning the international emphasis within the program curriculum, and a follow up questions concerning ideal emphasis. International content was a moderately emphasized topic $(\mathrm{M}=3.81)$ and this was less than students' ideal $(M=5.45)$. Although all segments agreed that an increased emphasis on International business was needed, the more experienced workers (manager $M=4.75$; executive $M=4.73$ ) did so less than the younger segments (young $\mathrm{M}=5.78$; standard $\mathrm{M}=5.50$ ).

\section{Delivery}

In terms of the delivery of material, students answered questions regarding the way information was delivered/acquired: face-2-face versus on-line, individual versus group, and hard vs. soft content. They were asked to consider these across the classes they were currently in and had already taken. Additionally, students were asked ideal delivery methods

$83 \%$ of content was delivered in person with the remaining $17 \%$ delivered on-line. Ideally, however, participants would prefer less face-2-face $(76 \%)$ with more on-line delivery $(23 \%)$. It is interesting to note that respondents would still prefer that the majority, three-quarters, of the program be delivered face-2-face and not online. This indicates a strong preference for traditional classroom learning.

The younger segments were open to on-line delivery and sought more on-line delivery (young 24\% online; standard 22\%) as expected. The manager segment, however, was the least open to on-line delivery, asking that, if anything, on-line delivery be decreased in the programs (manager 16\% online). Surprisingly, the most open to online delivery was the executive segment (executive 27\%). Given their age, job responsibilities, and likelihood of having a family, we assume this reflects more the need for flexibility than comfort and preference for on-line education.

$63 \%$ of knowledge acquisition was considered individual, and the remainder, group oriented. Ideally, participants would prefer an even stronger individual focus, 69\%. This preference for individual learning was magnified with age and experience (young 63\%, standard 66\%, manager 68\%, executive $74 \%$ ).

Nearly $40 \%$ of content was considered soft and students would prefer even more emphasis on this type of content $(45 \%)$. Interestingly, the preference for more soft content did not vary by segment. Some might consider that the executives with their considerable years of experience would have already mastered soft-skills such as presentations, writing, etc. However our results suggest that these skills remain necessary and that experience and practice with them does not negate their importance. See Table 2 for an overview of the pedagogy preferences by segment.

\section{Software}

Students were also asked what software they used during the program. EXCEL, SPSS, PASW, and SAS were specifically listed as well as an "other" option. 77\% of participants indicated that they had used EXCEL, while $5 \%$ or less indicated that they had used other statistical software. A follow up question asked what software, if any, they would like to see more heavily used or taught. Nearly $30 \%$ indicated that they would like to see more statistical software used or taught in their program. No differences were observed by segment.

\section{Grading}

Finally, participants answered a series of questions concerning grade components: discussions, formal presentations, cases, simulations, and formal papers. They were asked to consider these across the classes they were currently in and had already taken. 
Table 2

Differences in Pedagogy Preferences by Segment

\begin{tabular}{lc}
\hline Emphasis on International Topics & Mean \\
\hline Young & 5.78 \\
Standard & 5.50 \\
Manager & 4.75 \\
Executive & 4.73 \\
Overall & 5.45 \\
\hline Percentage of On-line vs. F2F Content & Percentage \\
\hline Young & $24 \%$ \\
Standard & $22 \%$ \\
Manager & $16 \%$ \\
Executive & $27 \%$ \\
Overall & $23 \%$ \\
\hline Percentage of Individual vs. Group Work & \\
\hline Young & $63 \%$ \\
Standard & $66 \%$ \\
Manager & $68 \%$ \\
Executive & $74 \%$ \\
Overall & $69 \%$ \\
\hline Percentage of Soft vs. Hard Content & $45 \%$ \\
\hline Young & $44 \%$ \\
Standard & $46 \%$ \\
Executive & $44 \%$ \\
Overall & $45 \%$ \\
\hline
\end{tabular}

In terms of in class discussion, the majority of students (79\%) indicated that it accounted for $20 \%$ or less of their course grade. Formal presentations were moderately more emphasized with the median of students indicating that presentations accounted for 31 to $50 \%$ of their grade. Simulations were the least emphasized course component with $70 \%$ indicating that they accounted for $10 \%$ or less of their grades (47\% indicated that it was $5 \%$ or less). Case analysis was polarized with $42 \%$ indicating it accounted for $20 \%$ or less of their grades while another $42 \%$ indicated $30 \%$ or more of their grades. Emphasis on written papers presented no clear pattern. Again, no differences were observed by segment.

\section{Discussion}

Current research suggests that top tier programs over emphasize hard-skill at the cost of soft skills (Bok 2006). Directly asking regional MBAs about the break down between hard and soft skills suggests that this follows in these programs with $60 \%$ of material considered hard. However, the other results presented above suggest differently. For example, logistics and forecasting computationally heavy subjects were the most commonly listed as insufficiently covered topics. Furthermore, less than 5\% of subjects indicated that they had used statistical software more complicated than EXCEL while nearly $30 \%$ listed this as a needed improvement to the programs. In terms of graded components, up to $20 \%$ of grades is based on class discussion with potentially another 30 to $50 \%$ coming from presentations. Additionally, although no clear pattern emerged in terms of formal written papers, the majority of participants $(23 \%)$ indicated that between 30 and $50 \%$ of their grades was based on formal written work. In combination, this suggests that soft-skills are a heavily graded component of these programs. Still, respondents in all segments indicated a preference for an increase focus on soft-skills.

Upon more careful analysis of these findings and synthesis of additional free responses and other data, we suggest two conclusions here. First, soft-skills are a necessary component of any MBA program irregardless of its ranking or target segment. However, they not only need to be assessed as graded components of a course but also taught. It is not enough to require and assess presentations as part of coursework, but these skills need to be taught. If excellent presentation or writing skills could be acquired just thru practice, we would have likely seen a decrease in the need for these skills in the executive segment, but we did not. A review of course offerings at all three studied programs confirmed that no specific course was designated to teach presentation or business writing to MBAs, yet almost all courses evaluated one or both of these skills. 
Second, the difference between regional programs and top tier programs is not in the break down between hard and soft skills but the emphasis within hard skills being more statistical/model driven/ computational in top tier programs and more theory driven in regional programs. We surmise, based on the desire for increased use of statistical software across all segments that the importance of data analysis and its application in business is of growing importance at all levels of an organization. However, we propose that what is important to regional MBAs is not the ability to build forecasting models or statistically analyze complex data, but the ability to understand and use that information.

\section{Satisfaction}

To assess satisfaction we collected traditional satisfaction measures such as "Overall are you happy with your decision to enter the program," "Given your current knowledge of the program, would you make the same decision to enter the program?" and "Do you feel the program was a good value for the money." We combined these three items into a single measure of satisfaction $(\alpha=0.93)$. Overall, respondents were satisfied $(M=5.29)$; however, satisfaction decreased with work experience (young $M=6.04$; standard $M=5.44$; manager $M=4.79$; executive $M=$ 4.00).

Additionally, we also collected measures of learning and rigor as these are common factors that affect student evaluations. We collected two items to assess rigor: "Overall how difficult/challenging do you find your program?" and "How rigorous are the grading standards?" We combined these items to form a single measure of rigor $(r=0.84)$. Overall respondents found the program moderately rigorous $(\mathrm{M}=4.12)$. Interestingly this did not vary by segment (young $M=4.11$; standard $M=4.00$; manager $M=4.00$; executive $M=4.33$ ). We also collected two measures of learning: "How many hours per week do you dedicate to your program including in class time and out of class time?" and "How much do you feel you have learned during your program?" On average, respondents reported spending 18 hours a week on their program and learning a considerable amount $(M=5.00)$. Both hours spent (young $M=23$ standard $M=16$; manager $M=15$; executive $M=13$ ) and learning (young $M=5.3$ standard $\mathrm{M}=5.1$; manager $\mathrm{M}=4.6$; executive $\mathrm{M}=4.0$ ) decreased with work experience. See Table 3 for an overview of satisfaction differences by segment.

Table 3

Satisfaction by Segment

\begin{tabular}{lc}
\hline Overall Satisfaction & Mean \\
\hline Young & 6.04 \\
Standard & 5.44 \\
Manager & 4.79 \\
Executive & 4.00 \\
Overall & 5.29 \\
\hline Assessment of Rigor & 4.11 \\
\hline Young & 4.00 \\
Standard & 4.00 \\
Manager & 4.33 \\
Executive & 4.12 \\
Overall & \\
\hline Assessment of Learning & 5.30 \\
\hline Young & 5.10 \\
Standard & 4.60 \\
Manager & 4.00 \\
Executive & 5.00 \\
Overall & Hrs. \\
\hline Hours Per Week Spent on Program & 23 \\
\hline Young & 16 \\
Standard & 15 \\
Manager & 13 \\
Executive & 18 \\
\hline
\end{tabular}


Discussion

As with undergraduates, rigor did not negatively correlate with evaluations. However, learning and satisfaction do seem correlated. Thus MBAs, unlike most undergraduates, are in fact assessing program effectiveness based on learning. This would suggest that programs designed to attract more mature segments need to formulate curriculums that better meet and address the learning goals of these segments. Furthermore, from our analysis we can suggest that these goals vary significantly from less experienced students. We discuss these differences and make recommendations in the conclusion section of this paper.

\section{Limitations}

We surveyed three AACSB accredited, non-urban, regional MBA programs. Furthermore, all three schools offered both full-time and part-time programs but did not distinguish among these programs. This high degree of similarity allowed us to analyze our results across schools; however, it also limited our generalization. For example urban schools may have more nuanced segments given that they probably represent a higher degree of diversity. Furthermore, surveying only three schools has provided us with a small sample of 102 students from which segmentation has been determined. A much larger sample size would have supplied a stronger foundation to segment the MBA regional market.

\section{CONCLUSION}

\section{Recommendations}

Much MBA research focuses on top tier programs assuming that what is done at top tier programs is replicated at regional programs. Furthermore, the underlying assumption in this research is that there is a best model that should be applied to all MBA programs. Although our research on regional programs does support the idea of a high degree of consistency across MBA programs, we do find several notable differences. Most importantly, top tier programs have a relatively homogeneous target segment with a narrow age range, consistent work experience, and similar career goals. In contrast, regional programs attract a multitude of segments. The four clearly distinguished segments are:

(1) Young: comprising of recent graduates looking for salary and job search opportunities.

(2) Standard: are most similar to top tier program students with their moderate work experience and career change and salary goals.

(3) Manager: consisting of experienced professionals that are looking for further career advancement.

(4) Executive: involving professionals motivated by personal achievement.

Understanding differences among the segments is crucial for the success of regional programs. Our results showed declining satisfaction and learning with work experience, suggesting that regional programs need to actively segment their markets based on work experience and build unique curriculums for each targeted segment. For example, the executive segment - with their need for personal achievement - is better addressed thru individual than group learning. Furthermore, we propose they have the highest need for flexibility and although on-line courses may provide this flexibility this is likely not their preference. Increased scheduling flexibility and more interactive online resources are suggested for this segment.

When designing programs for managers and executives it is important to leverage and then enhance their work experience as they are not career switchers. This may suggest that regional programs need to be designed to specifically support local industries so programs in Detroit, Michigan may need to focus on manufacturing, union negotiations, and logistics. In contrast, a program in Pensacola, Florida may need to focus on customer satisfaction, hospitality, and hotel and restaurant management. Or a program in Johnson City, Tennessee may need to focus on health promotions, medical data storage, and non-profit. In contrast, the limited experience of the young and standard segment in combination with their developing career goals suggests a more generalized program with heavy emphasis on experiential learning. Key to success in these programs is abundant practical and applied study in a variety of areas. 
Despite these differences among segments, several general conclusions about regional programs can also be drawn. Regional MBAs emphasize more hard skills than soft ones (just as top tier schools). However, given the limited use of advanced statistical software like SPSS or SAP, and the lack of computationally heavy courses such as forecasting and logistics, the hard skills being taught at these programs appear to lag behind top tier programs. Although this may actually reflect a difference in segment needs, if over 50\% of top tier programs graduates go into to financial services their need for computationally driven forecasting models is going to be significantly higher than this need in the regional MBA market.

The need for soft-skills, however, is relatively career independent and further as our results show equally important at all levels of the organization from early career to senior management. We suggest that regional programs not only assess these skills but actively teach key soft skills such as oral and written communication.

What is clear from this research is that regional MBA programs attract a broad range of segments and to best meet these segments' needs, these programs need to design programs specifically tailored to their target segments. A one size fits all approach to the regional MBA fails to prepare the students to act in the workplace according to their goals and needs.

\section{AUTHOR INFORMATION}

Dr. Kirsten Passyn is an Assistant Professor of Marketing and Management at the Franklin P. Perdue School of Business, Salisbury University, Salisbury, Maryland. She received her Ph.D. from Penn State and concluded a postdoc at Wharton. Her teaching and research interests include Consumer Behaviour, International Marketing, Marketing Principles. She is currently involved in MBA Curriculum design for the Perdue School. Email: kapassyn@salisbury.edu

Dr. Memo Diriker, is the Founding Director of the Business, Economic, and Community Outreach Network $($ BEACON). Dr. Diriker specializes in the use of "Scenario Analysis," and in "Demographic, Business, and Economic Trend Forecasting." His current research focuses on the "Three Es: Effectiveness, Efficiency, and Evidence." He is especially interested in exploring the successful deployment of the "Three Es" concept in MBA program design. Email: mfdiriker@salisbury.edu

\section{REFERENCES}

1. Abelson, A. (2010). Why Average MBA Age is Trending Down. Retrieved From http://www.bschooladmissionformula.com.

2. Bok, D. (2006). Our Underachieving Colleges. Princeton, NJ: Princeton University Press.

3. Chapman, R. G. (1998). MBA Quality Signals. Journal of Marketing for Higher Education, 8(4), pp. 2948.

4. Cullen, P. G. (2007). Living with Conflicting Institutional Logistics: The Case of the U.K. and U.S. Research Led Business Schools. (Unpublished Doctoral Thesis), University of Cambridge, UK.

5. Dailey, L., Anderson, M., Ingenito, C., Duffy, D., Krimm, P., \& Thomson, S. (2006). Understanding MBA Consumer Needs and the Development of Marketing Strategy. Journal of Marketing for Higher Education, 16(1), pp.143-158.

6. Datar, S.M., Garvin, D.A., \& Cullen, P.G. (2010). Rethinking the MBA: Business Education at a Crossroads. Boston: Harvard Business Press.

7. Enbar, N. (1999). Second-Tier B-Schools: Worth a Second Look. BusinessWeek. Retrieved from http://www.businessweek.com.

8. Hsu, M.K., Chao, G.H., \& James, M.L. (2009). An Efficiency Comparison of MBA Programs: Top 10 Versus Non-Top 10. Heldref Publications.

9. Lawton, L., \& Lundsten, L.(1998). Contrasts Between Benefits Expected and Delivered Among MBA Inquirers, Students, and Graduates. Journal of Marketing for Higher Education, 8(3), pp15-29.

10. Rond, M. D., \& Miller, A. M. (2005). Publish or Perish: Bane or Boon of Academic Life. Journal of Management Inquiry, 14, pp.321 -329. 
11. Schoemaker, Paul, J. H. (2008). The Future Challenges of Business: Rethinking Management and Education Research. California Management Review, 50, pp.119-139.

12. Van de Ven, A. H., \& Johnson, P. (2006). Knowledge for Theory and Practice. Academy of Management Review, 31, pp. 802-809. 


\section{APPENDIX A - MBA SURVEY QUESTIONNAIRE}

\section{Segmentation}

(1) How old are you?

(2) What is your gender?

(3) How many years of work experience do you have?

(4) Are you enrolled in a full-time, part-time, or executive program?

(5) Are you currently working full time?

(6) What was your primary goal in enrolling in your degree program?

\section{Pedagogy}

(1) What subject areas are covered in your program?

(2) Is your study predominately domestic or internationally focused? (For example when you talk about marketing, is it predominately concerned with the home market or also other global markets? Consider both within specific courses as well as across the program.)

(3) Would you like to see more or less international focus in your program?

(4) What percentage of your course is traditional face-to-face versus on-line?

(5) What percentage traditional face to face versus on-line would you consider ideal?

(6) What percentage of your workload is completed individually versus in groups?

(7) What percentage of group versus individual work would you consider ideal?

(8) How much emphasis is placed on hard versus soft skills in your program? (Hard skills could be defined as knowledge on business theory more technical and quantitative, whereas soft skills are more qualitative and approach-based such as presentation, public-speaking, and interview skills).

(9) What percentage of hard versus soft skills would you consider ideal? What programs and software packages have you been required to use/learn during your program?

(10) What programs or software would you like to see used (or used more heavily) in your program?

(11) Is in-class participation/discussion a graded component of your class? How heavily emphasized is this component?

(12) Does your program require formal presentations? How heavily emphasized is this component?

(13) Does your program require case analysis? How heavily emphasized is this component?

(14) Does your program require simulations? How heavily emphasized is this component?

(15) Does your program require research papers? How heavily emphasized is this component?

\section{Satisfaction}

(1) Overall, are you happy with your program experience?

(2) Given your current knowledge of the program, would you make the same decision to enter the program?

(3) Do you feel the program was a good value for the money?

(4) Overall how difficult/challenging do you find your program?

(5) How high would you assess the grading standards? (Very low=very easy to receive A; very high=difficult/impossible to receive A).

(6) On average how many hours a week do you allocate to your MBA program? (Include all school related activities, homework, in-class time, checking school email etc., in what you would consider a normal week.)

(7) Do you feel you have learned much in your program? 